Vol. 4, No. 2, Nopember 2018

p-ISSN: 2442-8884 / e-ISSN: 2541-4542

J-Kesmas

Jurnal Kesehatan Masyarakat

\title{
FAKTOR YANG MENDORONG PENCAPAIAN K4 KUNJUNGAN IBU HAMIL DI PUSKESMAS ANREAPI KABUPATEN POLEWALI MANDAR
}

\author{
Nur Rahmatia ${ }^{1}$, Muh Anwar ${ }^{2}$, Sukmawati $^{3}$ \\ Fakultas Kesehatan, Universitas Al Asyariah Mandar \\ email: Nurrahmatia008@gmail.com
}

\begin{abstract}
ABSTRAK
Kehamilan merupakan proses alamia yang di alami oleh setiap wanita. Lama kehamilan sampai atrem adalah 280 sampai 300 hari atau 39-40 minggu, sehingga selamamasa tersebut ibu hamil memerlukan pengawasan yang tepat. Janin dalam kandungan berkembang seiring usia kehamilan, maka apabila tidak dilakukan pengawasan bisa menyebabkan masalah, baik dalam kehamilan, persalinan dan nifasnya, bisa juga mengakibatkan kematian ibu dan bayi. Jenis penelitian yang digunakan adalah kualitatif dan subjek penelitiannya adalah informan biasa sebanyak tujuh, informan kunci sebanyak dua orang penentuan sampel dipilih secara purposive sampling yaitu sampel diambil bukan tergantung pada populasi melainkan disesuaikan dengan tujuan penelitian.Hasil penelitian dari 7 responden menunjukkan bahwa kunjungan ibu hamil ke Puskesmas Anreapi, keluarga sangat mendukung jika melakukan pemeriksaan kehamilan namun ada juga ibu hamil yang biasa melakukan pemeriksakan kehamilannya jika ada keluhan-keluhan yang di rasakan oleh ibu hamil tersebut. Disimpulkan bahwa sebagian besar keluarga mendukung untuk melakukan pemeriksaan kehamilan dan di puskesmas Anreapi itu sudah mencapai target kunjungan K4 ibu hamil
\end{abstract}

Kata Kunci : K4 Ibu hamil, Janin

\section{PENDAHULUAN}

Angka Kematian Ibu (AKI) adalah indicator kritis status kesehatan para perempuan. Kematian seorang ibu dalam keluarga memiliki dampak hebat, tidak hanya dalam hal kehilangan suatu kehidupan, namun juga karena efeknya pada kesehatan dan usia hidup anggota keluarga yang ditinggalkan.

Penyebab langsung kematian ibu adalah komplikasi yang terjadi selama kehamilan, kelahiran atau nifas. Kebanyakan kematian ibu di Indonesia
(75-85\%) berkaitan dengan satu atau panduan dari tiga komplikasi utama : pendarahan, infeksi dan eklamsia Utomo and kak dalam WHO (2007 : C60). Penyebab pendarahan, infeksi dan eklamsia beragam antar masyarakat. Kematian akibat pendarahan bisa di sebabkan karena anemia selama hamil. Studi berbasis rumah sakit menunjukan bahwa resiko kematian perempuan dengan anemia adalah empat kali dibandingkan perempuan non-anemik, iskandar dkk dalam WHO (2007 : C- 
Vol. 4, No. 2, Nopember 2018

p-ISSN: 2442-8884 / e-ISSN: 2541-4542

J-Kesmas

Jurnal Kesehatan Masyarakat

60). Bila Hb kurang dari $8 \mathrm{gr} \%$, resiko

kematian menjadi 8 kali lebih tinggi, belsey dan roystin dalam WHO (2007 : C-60).

Terdapat beberapa indikator yang digunakan untuk mengukur status kesehatan ibu pada suatu wilayah, salah satunya yaitu Angka Kematian Ibu (AKI). AKI merupakan salah satu indikator yang peka terhadap kualitas dan aksesibilitas fasilitas pelayanan kesehatan. Berdasarkan Survei Demografi dan Kesehatan Indonesia (SDKI) tahun 2012, AKI (yang berkaitan dengan kehamilan, persalinan, dan nifas) sebesar 359 per 100.000 kelahiran hidup.Angka ini masih cukup tinggi jika dibandingkan dengan negara-negara tetangga di Kawasan ASEAN. Pada tahun 2007, ketika AKI di Indonesia mencapai 228, AKI di Singapura hanya 6 per 100.000 kelahiran hidup, Brunei 33 per 100.000 kelahiran hidup, Filipina 112 per 100.000 kelahiran hidup, serta Malaysia dan Vietnam sama-sama mencapai 160 per 100.000 kelahiran hidup.

Program pembangunan kesehatan di Indonesia dewasa ini masih diprioritaskan pada upaya peningkatan derajat kesehatan ibu dan anak. Terutama pada kelompok yang paling

rentan kesehatan yaitu ibu hamil, bersalin dan bayi pada masa perinatal,hal ini di tandai dengan tingginya Angka Kematian Ibu (AKI) dan Angka Kematian Bayi (AKB).

Profil kesehatan Sulawesi Barat dimana cakupan K1 pada tahun 2012 sebesar 96,5\%, sedangkan untuk cakupan K4 sebesar 77,6\%.

Sementara untuk tingkat Kab. Polewali Mandar tahun 2011 cakupan K1 sebesar 99,95\%, tahun 2012 sebesar 94,9\% dan cakupan K4 tahun 2011 sebesar 81,1\% dan pada tahun 2012 sebesar 78,3\%. Jika dibandingkan dengan target yang ingin dicapai dalam pelaksanaan pembangunan kesehatan untuk tahun 2010 yaitu jumlah K1 sebesar $90 \%$ dan K4 sebesar $80 \%$, maka data tersebut untuk K1 sudah mencapai target sementara untuk cakupan K4 belum mencapai target.

Kemudian ibu juga mempengaruhi kematian bayi.Ada banyak factor yang mempengaruhi tingkat angka kematian bayi (AKB) tetapi tidak mudah untuk menemukan faktor yang paling dominan. Tersedianya berbagai fasilitas atau factor aksesibilitas dan pelayanan kesehatan masyarakat dari tenaga medis yang terampil, serta kesediaan 
Vol. 4, No. 2, Nopember 2018

J-Kesmas

p-ISSN: 2442-8884 / e-ISSN: 2541-4542

Jurnal Kesehatan Masyarakat

masyarakat untuk merubah kehidupan

Berdasarkan Laporan Tahunan

tradisional ke norma kehidupan

KIA ditemukan Penyebab kematian Ibu

moderen dalam bidang kesehatan pada tahun 2011 didominasi oleh faktor merupakan faktor yang sangat berpengaruh terhadap angka kematian bayi (AKB). Penyebab kematian bayi terbanyak adalah kasus asfiksia dan sebagian besar terjadi di rumah sakit (Dinkes Sulbar, 2006 :17). Data angka kematian ibu (AKI) dan angka kematian bayi (AKB) tersebut bahwa derajat kesehatan khususnya kesehatan ibu dan anak masih merupakan permasalahan bagi Provinsi Sulawesi Barat dan khususnya Kabupaten Polewali Mandar.

Di Kabupaten Polewali Mandar sendiri, Angka Kematian Ibu pada tahun 2006 tercatat 22 orang. Untuk tahun 2007 , tercatat 15 orang dan tahun 2008 tercatat $17 \mathrm{ibu}$ maternal dan ditahun 2009 ada 12 kematian ibu yang di laporkan. Ditahun 2010 ditemukan sebanyak 13 kematian ibu dan tahun 2011 masih tetap ditemukan sebanyak 13 kematian ibu. Dengan upaya-upaya penuruan Kematian Ibu di Kabupaten Polewali ditahun 2012 hanya bisa ditekan menjadi 12 Kematian ibu dari 8.749 kelahiran hidup, Tahun 2013 angka kematian yang dilaporkan sebanyak 11 kematian ibu dari 8.355 kelahiran hidup. 
Vol. 4, No. 2, Nopember 2018

p-ISSN: 2442-8884 / e-ISSN: 2541-4542

J-Kesmas

Jurnal Kesehatan Masyarakat

tinggi (137 per 100.000 kelahiran

hidup) bila dibandingkan dengan target

102 per 100.000 kelahiran hidup yang

harus dicapai ditahun 2015 atau sekitar

hanya 8 kematian ibu, dan di tahun

2014 angka kematian ibu sudah berada

di bawah target yaitu 5 kematian Ibu,

hal ini terjadi karena kerjasama lintas

sektoral yang saling terkait yang

berupaya semaksimal mungkin untuk

menurunkan angka kematian Ibu di

bawah target nasional. Semoga

pencapaian - pencapaian ini dapat di

pertahankan di tahun - tahun

mendatang.

Pelayanan kesehatan ibu dan anak meliputi Antenatal Care sampai post partum. Untuk antenatal Care yang menjadi indicator adalah kunjungan pertama ibu hamil pada trimester pertama dan keempat pada trimester tiga ke tempat pelayanan untuk memeriksakan kehamilannya. Gambaran besaran ibu hamil yang telah mendapatkan pelayanan ibu hamil sesuai standar serta paling sedikit empat kalikunjungan (K4) selama hamil sebanyak 169 dari seluruh ibu hamil sebanyak 233 orang atau sekitar 72\% (Puskesmas Anreapi), dari data di atas dapat di simpulkan bahwa masih banyak ibu hamil yang tidak 
Vol. 4, No. 2, Nopember 2018

p-ISSN: 2442-8884 / e-ISSN: 2541-4542

J-Kesmas

Jurnal Kesehatan Masyarakat

seseorang yang memungkinkan untuk mendapatkan hal-hal yang tersirat tentang sikap, kepercayaan, motivasi dan prilaku individu.Penelitian kualitatif digunakan untuk menyelidiki, menemukan, menggambarkan serta menjelaskan kualitas atau keistimewaan dari pengaruh sosial yang tidak dapat dijelaskan, diukur atau digambarkan melalui pendekatan kuantitatif. Penelitian kualitatif bertujuan untuk penyelidikan dan mencari jawaban atas suatu pertanyaan, dilakukan secara sistematis, mengumpulkan fakta, menghasilkan suatu temuan serta mengurai pengalaman hidup dan memberinya makna. ( Pollit, Beck dan Hungler, 2001 dikutip dalam Saryono dan Anggraeni, 2010).

Teknik pengumpulan data yang digunakan wawancara mendalam (indepth interview) untuk memperoleh keterangan dari informan untuk penelitian dengan cara tanya jawab sambil bertatap muka antara peneliti dan informan dengan pedoman umum, peneliti mencantumkan isu-isu yang harus diliput tanpa menentukan urutan pertanyaan, pedoman wawancara digunakan untuk mengingatkan peneliti mengenai aspek yang harus dibahas.

Wawancara dengan cara umum
ini dapat berbentuk wawancara terfokus, yaitu wawancara yang mengarah pembicaraan hal-hal tertentu dari kehidupan/ pengalaman subyek (Poerwandari, 2009).

Wawancara merupakan tehnik komunikasi antara peneliti dengan informan.Peneliti sebagai interviewer harus responsif, menyesuaikan diri dengan informan, tidak memberikan kesan negatif, memberi pengertian kepada informan tentang pentingnya informasi yang diberikan.Wawancara memerlukan waktu kurang lebih 40-60 menit, hal ini dimaksudkan agar informan tidak terlaluh lelah sehingga tidak mempengaruhi kondisi dan jawaban atas pertanyaan penelitian.Pengumpulan data tidak hanya wawancara, peneliti juga membuat catatan lapangan (field note) yang berisikan tentang tanggal, waktu, dan informasi dasar tentang suasana saat wawancara seperti tatanan lingkungan, interaksi sosial dan aktifitas yang berlangsung saat wawancara. Catatan lapangan pada penelitian kualitatif dibuat segera setelah proses wawancara selesai dari masing-masing informan, peneliti juga menggunakan alat bantu HP/MP4 untuk merekam 
Vol. 4, No. 2, Nopember 2018

J-Kesmas

Jurnal Kesehatan Masyarakat

informasi dari informan ( Saryono dan anggraeni, 2009).

Tekhnik analisa data menggunakan model analisa editing. Peneliti membaca seluruh hasil wawancara sampai habis serta mencari segmen-segmen penuh arti dalam unitunit suatu ketika segmen dikenali dan ditinjau interpreter dikembangkan satu rencana pengelompokan.

Kemudian membeti kode-kode sesuai untuk memilih jenis dan mengorganisasikan data, kemudian mencari struktur dan pola-pola yang menghubungkan kategori-kategori pokok.

Setelah data sekunder dan data primer dikumpulkan, kemudian dilakukan pengolahan data dengan tahapan sebagai berikut :

1. Peneliti mengorganisasikan semua data atau gambaran menyeluruh tentang fenomena pengalaman yang telah dikumpul.

2. Membaca data secara keseluruhan dan mambuat catatan pinggir mengenai data yang dianggap penting kemudian melakukan pengkodean data.

3. Mengelompokan makna pernyataan yang dirasakan oleh informan dengan melakukan horizonaliting
p-ISSN: 2442-8884 / e-ISSN: 2541-4542

yaitu setiap pernyataan pada awalnya diperlukan memiliki nilai yang sama. Selanjutnya, pernyataan yang tidak relevan dengan topik dan pernyataan maupun pernyataan yang bersifat repetitive atau tumpang tindih dihilangkan, sehingga yang tersisa hanya horizons artinya tekstural dan ungsur pembentukan atau penyusunan dari penomena yang tidak mengalami penyimpangan.

4. Selanjutnya peneliti mengembangkan uraian secara keseluruhan dari hasil wawancara yang didapat dari informan tentang pengalamannya.

5. Peneliti kemudian memberi penjelasan secara naratif mengenai esensi dari fenomena yang diteliti dan mandapatkan makna pengalaman informan mengenai phenomena tersebut.

6. Selanjutnya membuat laporan pengalaman setiap informan setelah itu gabungan dari gambaran itu ditulis (dikutip dalam Saryono dan Anggraeni, 2010 )

\section{HASIL}

\section{Gambaran Umum Lokasi Penelitian}

Kecamatan Anreapi Kabupaten Polewali Mandar dengan Luas Wilayah 
Vol. 4, No. 2, Nopember 2018

J-Kesmas

Jurnal Kesehatan Masyarakat

124.62 KM2. Di Kecamatan Anreapi terdiri dari 1 Kelurahan dan 4 Desa yakni Kelurahan Anreapi, Desa Duampanua, Desa Pappandangan, Desa Kelapa dua, dan Desa kunyi. Dengan jarak ibu kota kecamatan Anreapi dari pusat pemerintahan, Provinsi 216 KM, Kabupaten 7 KM.

1. Tentang Pemeriksaan Kehamilan K4 Berdasarkan hasil penelitian yang di lakukan di Kec. Anreapi kabupaten polewali mandar bahwa semua ibu hamil rutin memeriksakan kehamilannya di petugas kesehatan yang ada di pustu maupun di puskesmas dimana pemeriksaan itu di lakukan satu kali setiap bulannya.

Kemudian adapun informasi yang di dapatkan oleh ibu hamil tentang pemeriksaan apa saja yang di lakukan oleh ibu hamil misalkan pemeriksaan ANC, pemeriksaan tekanan darah, pemeriksaan tinggi badan, pemeriksaan lingkar lengan, pemeriksaan tinggi pundus,kemudian semua ibu hamil sudah mendapatkan penyuluhan pentingnya memeriksakan kehamilan agar ibu hamil itu mau memeriksakan kehamilannya ada program yang telah di lakukan seperti kelas ibu hamil.
p-ISSN: 2442-8884 / e-ISSN: 2541-4542

2. Dukungan suami memiliki peranan yang sangat penting secara psikologis maupun mental. Sebagian besar informan menyatakan bahwa semua mendapatkan dukungan dari suami dikarenakan itu demi kebaikan ibu hamil itu sendiri bentuk dukungan yang diberikan misalnya mengantar setiap melakukan pemeriksakan kehamilan, mengetahui perkembangan janin yang di kandung serta kesehatan tetap terjaga dengan atur - aturan yang di anjurkan oleh petugas kesehatan atau ibu bidan.

3. Tradisi merupakan perbuatan yang dilakukan berulang-ulang dalam bentuk yang sama misalkan kebiasaan turun-temurun (dari nenek moyang) yang masih di jalankan atau dilakukan dalam masyarakat.

Berdasarkan penelitian informan tentang tradisi atau adat istiadat ada beberapa informan menyatakan bahwa tradisi yang dilakukan turuntemurun masih di jalankan atau dilakukan seperti 7 bulanan, larangan-larang yang tidak dapat dilakukan seorang ibu hamil dalam beberapa faktor yang dikatakan dukun (paranormal).

\section{PEMBAHASAN}


Vol. 4, No. 2, Nopember 2018

J-Kesmas

Jurnal Kesehatan Masyarakat

\section{A. Tentang Pemeriksaan Kehamilan}

K4

Berdasarkan hasil penelitian yang di lakukan di Kec. Anreapi kabupaten polewali mandar bahwa semua ibu hamil rutin memeriksakan kehamilannya di petugas kesehatan yang ada di pustu maupun di puskesmas dimana pemeriksaan itu di lakukan satu kali setiap bulannya.

Kemudian adapun informasi yang di dapatkan oleh ibu hamil tentang pemeriksaan apa saja yang di lakukan oleh ibu hamil misalkan pemeriksaan ANC, pemeriksaan tekanan darah, pemeriksaan tinggi badan, pemeriksaan lingkar lengan, pemeriksaan tinggi pundus,kemudian semua ibu hamil sudah mendapatkan penyuluhan pentingnya memeriksakan kehamilan agar ibu hamil itu mau memeriksakan kehamilannya ada program yang telah di lakukan seperti kelas ibu hamil.

Kunjungan pemeriksaan kehamilan merupakan salah satu bentuk perilaku. Menurut Lawrence Green, faktor - faktor yang berhubungan dengan perilaku ada 3 yaitu: faktor predisposisi, faktor pendukung, dan faktor pendorong. Yang termasuk faktor predisposisi diantaranya : pengetahuan, sikap, kepercayaan, tradisi, dan nilai. Sedangkan yang termasuk faktor pendukung adalah ketersediaan sarana-sarana kesehatan, dan yang terakhir yang termasuk faktor pendorong adalah sikap dan perilaku petugas kesehatan (Notoatmodjo, 2003).

Secara teori memang perubahan perilaku atau mengadopsi perilaku baru itu mengikuti tahap tahap, yakni melalui proses perubahan: pengetahuan (knowledge), sikap (attitude), praktik (practice) atau "KAP". Beberapa penelitian telah membuktikan hal itu, namun penelitian lainnya juga membuktikan bahwa proses tersebut tidak selalu seperti teori diatas (K-AP), bahkan di dalam praktik seharihari terjadi sebaliknya. Artinya, seseorang telah berperilaku positif, meskipun pengetahuan dan sikapnya masih negatif (Notoatmodjo, 2003).

\section{B. Dukungan Suami}

Dukungan suami memiliki peranan yang sangat penting secara psikologis maupun mental. Sebagian 
Vol. 4, No. 2, Nopember 2018

J-Kesmas

Jurnal Kesehatan Masyarakat

besar informan menyatakan bahwa semua mendapatkan dukungan dari suami dikarenakan itu demi kebaikan ibu hamil itu sendiri bentuk dukungan yang diberikan misalnya mengantar setiap melakukan pemeriksakan kehamilan, mengetahui perkembangan janin yang di kandung serta kesehatan tetap terjaga dengan atur - aturan yang di anjurkan oleh petugas kesehatan atau ibu bidan.

Dukungan sosial yang paling diperlukan bagi seorang ibu dalam menghadapi periode perinatal adalah keluarga ( Indriyani, 2013 ). Ibu hamil selama sekitar 9 bulan mengalami dan merasakan fase fase pertumbuhan janin yang membutuhkan dorongan mental dari lingkungan ( Anshor dan Abdullah Ghalib, 2010 ). Dalam hal ini fungsi dukungan keluarga bagi ibu hamil yakni akan mendatangkan rasa senang, rasa aman, rasa puas, dan rasa nyaman yang akan membuat ibu hamil akan merasa mendapat dukungan secara emosional yang akan mempengaruhi kesehatan jiwanya ( Mahmunah, 2010 ). Pada masa kehamilan, peran suami sangat penting untuk memotivasi istri terus
p-ISSN: 2442-8884 / e-ISSN: 2541-4542

menjaga kesehatan dengan mengomsumsi makanan yang bergizi, dengan istirahat yang cukup, terus bersabar serta mendampinginya setiap memeriksakan kehamilan (Anshor dan Abdullah Ghalib, 2010). Manuaba dkk ( 2003 ), menyatakan bahwa ibu hamil yang kekurangan dukungan psikologis dan sosial budaya dari keluarga yang paling dekat, khususnya suami, akan cenderung mengalami strees pada kehamilan.

Mahmunah ( 2010 ) juga menambahkan bahwa jika seluruh keluarga mengharapkan kehamilan, mendukung bahkan memperlihatkan dukungannya dalam berbagai hal, maka ibu hamil akan merasa lebih percaya diri, lebih bahagia dan siap menjalani kehamilan, persalinan dan masa nifas.

Penelitian ini sejalan dengan penelitian yang dilakukan Ira dkk, dengan judul pemanfaatan Antenatal Care (ANC) oleh ibu hamil pada masyrakat Desa Makupa Kecamatan Lambandia Kabupaten Kolaka Timur tahun 2015. Adapun hasil penelitian yang diperoleh yaitu berdasarkan hasil wawancara diperoleh informan bahwa, (1) Anjuran untuk 
Vol. 4, No. 2, Nopember 2018

J-Kesmas

Jurnal Kesehatan Masyarakat

memeriksakan kehamilan berasal dari dukungan suami, keluarga dan kemauan sendiri. (2) Pemeriksaan kehamilan biasa ditemani dengan suami dan keluarga (3) Pemeriksaan kehamilan selalu diingatkan oleh keluarganya.

\section{Tradisi}

Tradisi merupakan perbuatan yang dilakukan berulang-ulang dalam bentuk yang sama misalkan kebiasaan turun-temurun (dari nenek moyang) yang masih di jalankan atau dilakukan dalam masyarakat.

Berdasarkan penelitian informan tentang tradisi atau adat istiadat ada beberapa informan menyatakan bahwa tradisi yang dilakukan turun-temurun masih di jalankan atau dilakukan seperti 7 bulanan, larangan-larang yang tidak dapat dilakukan seorang ibu hamil dalam beberapa faktor yang dikatakan dukun (paranormal).

Menurut Foster dan Anderson (dalam Djoht, 2002), kebudayaan kesehatan mengkaji masalahmasalah kesehatan dan penyakit dari dua kutub yang berbeda yaitu kutub biologi (pertumbuhan dan perkembangan manusia, peranan penyakit dalam evolusi manusia dan
p-ISSN: 2442-8884 / e-ISSN: 2541-4542

paleopatologi atau studi mengenai penyakit-penyakit purba) dan kutub sosial budaya (sistem medis tradisional atau etnomedisin, masalah petugaspetugas kesehatan, tingkah laku sakit, hubungan antara dokter pasien, dan dinamika dari usaha memperkenalkan pelayanan kesehatan kepada masyarakat tradisional). Dengan demikian kebudayaan kesehatan adalah disiplin ilmu yang memberi perhatian pada aspek-aspek biologi dan sosial-budaya dari tingkah laku manusia, terutama tentang cara-cara interaksi antara keduanya disepanjang sejarah kehidupan manusia, yang memengaruhi kesehatan dan penyakit pada manusia. Dari definisi yang dibuat oleh ahli antropologi, dapat disimpulkan bahwakebudayaan kesehatan mencakup: interpretasi berbagai macam masalah tentang hubungan timbal-balik biobudaya, antara tingkah laku manusia dimasa lalu dan masa kini dengan derajat kesehatan dan penyakit, tanpa mengutamakan perhatian pada penggunaan praktis dari pengetahuan tersebut; partisipasi profesional mereka dalam program-program 
Vol. 4, No. 2, Nopember 2018

p-ISSN: 2442-8884 / e-ISSN: 2541-4542

$\mathrm{J}$-Kesmas

Jurnal Kesehatan Masyarakat

yang bertujuan memperbaiki derajat kesehatan melalui pemahaman yang lebih besar tentang hubungan antara gejala bio-sosial-budaya dengan kesehatan, serta melalui perubahan tingkah laku sehat kearah yang diyakini akan meningkatkan kesehatan yang lebih baik.

\section{SIMPULAN}

1. Pemeriksaan Kehamilan K4 di Puskesmas Anreapi Kec. Adreapi Kabupaten Polewali Mandar itu sudah cukup baik karna sudah mencapai target kunjungan $\mathrm{K} 4 \mathrm{ibu}$ hamil.

2. Dukungan Suami terhadap kunjungan pemeriksaan ibu hamil ke Puskesmas Anreapi Kec. Anreapi Kabupaten Polewali Mandar sebagian besar suami mereka sangat mendukung pemeriksaan kehamilan.

3. sampai saat ini masih ada tradisi turun-temurun yang di lakukan masyarakat berulang-ulang dalam bentuk yang sama

\section{SARAN}

1. Pemerintah lebih memaksimalkan program pelayanan kesehatan ibu dan anak di Kec. Anreapi Kabupaten Polewali Mandar
2. Di sarankan kepada semua ibu hamil agar rutin pemeriksaan kehamilan agar tercegah komplikasi

3. Perlu di tingkatkan lagi pelayanan atau penyuluhan kesehatan bagi ibu hamil agar pencapaian target kunjungan K4 itu maksimal.

4. Perlu di lakukan penelitian lebih lanjut dengan menggunakan rancangan metode analisis lain agar didapat hasil yang menjelaskan lebih menyeluruh tentang studi motivasi terhadap kunjungan ibu hamil.

\section{DAFTAR PUSTAKA}

Dinas Kesehatan. (2012). Survei Demografi dan Kesehatan Indonesia

Dinkes Sulbar. Angka Kematian Ibu (AKI) dan Angka Kematian Bayi (AKB).2014:

Dinas Kesehatan Polewali Mandar. 2010. Profil Kesehatan Pemerintah Kabupaten Polewali Mandar.

Hidayat, A. A. (2009). Metode penelitian \& tehnik analisa data. Salemba Medika: Jakarta.,

Puskesmas Anreapi, Laporan Rutin Puskesmas Anreapi (2015).

Saryono \& Anggraeni, D. M. (2010). Metodologi penelitian kualitatif dalam bidang kesehatan. Muha Medika: Yogyakarta.

Saryono dan anggraeni analisis data Jakarta 2007.2010 